\title{
JORGE FALCÓN
}

Escola de Comunicação e Artes - Pontificia Universidade Católica de Paraná (PUCPR) jorge.falcon@pucpr.br

\section{Reseña de evento científico}

\section{Reseña de la 32da Conferencia Mundial de la Sociedad Internacional para la Educación Musical (ISME) - Glasgow 2016}

El evento bienal de la ISME, Sociedad Internacional de Educación Musical es, sin lugar a dudas, el evento más grande e importante en lo que se refiere a educación musical en todo el mundo. La 32a edición reunió millares de personas de los cinco continentes, fue organizado por la propia asociación y tuvo como sede el Glasgow Concert Hall y el Royal Conservatory of Scotland.

Eventos de este porte sólo pueden ser realizados por organizaciones muy poderosas (el término poderosas es usado en este caso en el sentido de tener el poder de articular acciones a medio/largo plazo y a través de la coordinación de grandes equipos preparados y con experiencia) y esto se refleja permanentemente en cada detalle.

Como este fue mi primer ISME intentaré resumir rápidamente mi impresión de este evento en relación con otros eventos internacionales semejantes de los que participé, por lo tanto habrá un cierto grado (tal vez bastante alto) de subjetividad en mi relato.

Los tiempos manejados por la organización simbolizan claramente algunas de las cosas que voy a resaltar seguidamente. Yo hice mi inscripción para el ISME, 
el 31 de marzo de 2016, después de pasar por un largo proceso de selección que comenzó en octubre de 2015, y del cual fui informado desde 2014. Trabajos a medio/largo plazo como este permiten que la organización luzca impecable.

No tengo informaciones oficiales de números al respecto, pero creo que no debe haber habido menos de 2000 participantes, sin contar performers, ejecutantes y participantes de conciertos, shows y otros tipos de espectáculos.

Una de las mayores cualidades del ISME es la capacidad de ofrecer democráticamente al derecho al acceso a la educación musical a todo el mundo, objetivo que expresa explícitamente en su página oficial - https://www.isme.org. Si esto es puesto en práctica es lógico que emerjan una serie de consecuencias, muchas positivas y otras no tanto, que detallaremos más adelante. El hecho de permitir el acceso de tantas personas y trabajos diferentes, como decía, brinda la posibilidad, declarada en los principios de la asociación, de garantizar acceso a una cantidad significativa de información. Como participante uno se ve obligado a hacer una cuidadosa y programada selección para aprovechar al máximo posible cada día, corriendo el riesgo de perder trabajos que son ofrecidos en los mismos horarios. Personalmente, conforme mis propios intereses, me programé para acompañar los seminarios y comunicaciones sobre Assessment y, dentro de lo posible, los que tocaban el tema de la tecnología y educación. En el caso de que tuviera que desplazarme a otra sala corría el riesgo de perder el comienzo de la próxima. Una de las cuestiones operativas más significativas es que la puntualidad británica se hizo presente a cada minuto (valga el juego de palabras). Todos los eventos, desde las comunicaciones orales a los conciertos comenzaron en el marco de esa legendaria cualidad. Las comunicaciones orales en las que participé personalmente comenzaron exactamente en el horario indicado. La comparación con otros eventos me resultó inevitable.

Discursos cortos, equilibrados, bien humorados (sin exageraciones) y objetivos. Conciertos de altísima calidad. Equipo de logística y apoyo siempre sonrientes y extremamente dispuestos. Mucha información.

Los seminarios y comunicaciones abordaron los siguientes asuntos:

1. Educación del Músico Profesional.

2. Música en Educación Especial: Música y terapia, Música y medicina.

3. Tecnología Musical.

4. Espiritualidad y Educación Musical.

5. Pedagogías Aplicadas.

6. Assessment, Medición y Evaluación.

7. Investigación. 
8. El Sistema.

9. Jazz.

10. Fórum para Pedagogía Vocal e Instrumental.

11. Práctica Musical Comunitaria.

12. Educación Musical en la primera infancia.

13. Política: Cultura, educación y medios.

14. Salud y bienestar del Músico

15. Práctica e investigación en Educación Musical Integrada.

16. Música en Escuelas y Educación del Profesor.

Desde mi punto de vista, sentí un poco la necesidad de grupos de trabajo direccionados a psicología y cognición y a una visión más moderna y natural de enseñar y aprender teoría musical, en este caso haciendo foco en como renovar la metodología en dirección a una manera de entender la teoría de la música más alineada con nuestros tiempos (y con la música de nuestros tiempos).

Yendo concretamente a el tratamiento de asuntos específicos como assessment podríamos decir que la amplitud democrática de un asunto tan amplio y con posibilidades de abordaje tan diferentes, en virtud de un tema que es difícil de definir o delimitar por su propia esencia, generó que los trabajos presentados fueran muy diversificados, y a veces extremamente opuestos en metodologías, propuestas, resultados y objetivos. Las sesiones incluyeron trabajos de Hungría, Singapur y EUA, como muestra de la diversidad. Sumado a que cada persona persigue un objetivo y un objeto de investigación particular, la variedad oscila entre el caos, la sorpresa permanente y naturalmente, obviedades y trabajos tan específicos y regionales que se muestran poco aprovechables.

Por otro lado todo lo que tuve oportunidad de ver sobre tecnología me mostró que hay un gran gap entre la tecnología en si y lo que se hace con ella. Clases de piano por Instagram, aplicaciones sobre teoría tradicional que trabajan con contenidos semejantes a aquellos los con los que Beethoven tuvo que lidiar me hacen reflexionar si una revisión de los contenidos no sería obligatoria. Parece que estamos cambiando la manera de entregar aquello que se muestra, muchas y comprobadas veces, obsoleto. Claro, un crédito es necesario para que podamos entender que hacer con todo aquello que es increíblemente rápido, poderoso y nuevo para todos. La tecnología nos superará siempre, y como se dice en Brasil tendremos siempre que "correr atrás".

La Conferencia bianual ISME es un evento necesario, único y ofrece mucho 
para quien está dispuesto a aprovechar. Es un inestimable lugar para conocer gente, trabajos, hacer contactos, mostrar nuestro trabajo y recibir mucha información.

El lado negativo es que todo es muy rápido al punto de perder profundidad, ya que tanta información es imposible de absorber y probablemente perderemos algo que está pasando en otro lugar mientras hacemos otra cosa.

Los beneficios: acceso democrático, cantidad y variedad. El lado menos positivo: exceso de información y a veces falta de profundidad.

Organización impecable, espacios excelentes, espectáculos de primer nivel, mucha gente trabajando y muy bien preparada, de una amabilidad y una sonrisa permanente que dejan el gusto de "todo debería ser así siempre" son algunos de los puntos más altos.

Insisto, a pesar de algunas críticas hechas aquí, que eventos como este son no sólo necesarios como obligatorios para educadores musicales, por lo menos una vez en nuestra vida académica.

Yo, particularmente, prefiero repetir en Estambul 2018.

\section{Biografia del autor}

\section{Jorge Falcón}

jorge.falcon@pucpr.br

Jorge Falcón. Formado en Producción Musical por la Universidad Federal de Paraná y en Guitarra Clásica en el Conservatorio Juan José Castro. Magister por la Universidad Federal de Paraná en la línea de Teoría y Creación Musical en el área de análisis musical y cognición con el trabajo "Cuatro Criterios para el análisis musical basado en la percepción auditiva". Fue profesor de la Escuela de Música de Buenos Aires, en los cursos de Músico y Productor Profesional de Música. En Brasil participa desde 1996 como instrumentista, arreglador, productor artístico y musical de diversos grupos. Fue premiado en 2003 en la categoría Música Electrónico con el Premio Saul Trumpet. También recibió una mención como Mejor Arreglador. Co compuso la música para el film de animación Brichos que recibió el premio del Festival de Cine de Maringá (2007). Es coordinador del Curso de Licenciatura en Música y Profesor en la Pontificia Universidad Católica de Paraná, Brasil (en Curitiba). 